\title{
EMPREGOS FORMAIS E REMUNERAÇÕES NO RIO GRANDE DO NORTE (RN) ${ }^{1}$ FORMAL JOBS AND SALARIES IN RIO GRANDE DO NORTE (RN) \\ Bruno José Bezerra Silva ${ }^{2}$ e Pedro Balduino de Sousa Neto ${ }^{3}$
}

\section{RESUMO}

O comportamento dos empregos formais e as remunerações estabelecidas são importantes para a dinamização econômica local. Seguindo essa linha de raciocínio, o presente trabalho objetiva analisar a dinâmica de empregos formais e remunerações no Rio Grande do Norte, no período de 2015-2016. A realização do estudo se respaldou-se na definição de conceitos dos termos. O processo metodológico sustenta-se na interpretação de informações extraídas de fontes oficiais e, dessa forma, a pesquisa contém dados secundários. Em seus resultados, o artigo apresenta análises sob o número de empregos formais nos setores econômicos; a remuneração média etc.

Palavras-chave: Remuneração. Escolaridade. Emprego.

\section{ABSTRACT}

The behavior of established and formal jobs and salaries are important for boosting local economy. Following this line of such reasoning, the current study aims to analyze the dynamics of formal jobs and salaries in Rio Grande do Norte, between 2015 and 2016. The completion of the study was based on the definition of the concepts of the terms. The methodological process is sustained in the interpretation of the information extracted from official sources; hence, the research contains secondary data. So, before the data exposed, three facts: 1) the formal jobs in economic sectors have reduced; 2) the increase in education points to the salary increment; 3) women continue to receive less than men, despite the continual advances in recent years.

Keywords: Remuneration. Schooling. Job.

\footnotetext{
${ }^{1}$ Artigo original.

${ }^{2}$ Graduação em Ciências Econômicas (UERN). Especialização em Gestão Pública (IFRN). Mestrando em Economia (UERN). E-mail: brunojosebj19@gmail.com

${ }^{3}$ Graduação em Administração (UERN). Especialização em Educação Ambiental e Geografia do Semiárido (IFRN).

E-mail: pedro_balboino@hotmail.com
} 


\section{INTRODUÇÃO}

No planeta, pode-se dizer que, no decorrer da década 1930, os países industrializados conviveram com o crescimento econômico, com avanços científicos, melhorias nas condições de vida, entre outros fatores. No entanto, nos últimos anos, nota-se que um cenário de crise e dívidas vem se tornando cada vez mais aparente, como afirma Woleck (2002). O autor ainda explica que o declínio na geração de emprego aponta para a possibilidade de um cenário social conturbado em diversos locais e, a partir disso, muitas pessoas optam pelo exercício do trabalho autônomo.

$\mathrm{Na}$ América Latina, a abordagem do emprego era cercada pela necessidade de aumentar a capacidade produtiva; isto é, pela necessidade de industrialização. É diante desse contexto que os fatores associados ao emprego, à distribuição de renda e à superação da pobreza iniciam, de maneira mais sistemática, na década de 1950 (MATTOS; LIMA, 2015).

No Brasil, nos últimos anos, tais fatores foram relevantes para o país, pois indicaram crescimentos singulares, o que não era visto desde década de 1970. O cenário cheio de incoerências internas proporcionou o aumento da geração de emprego, da renda, políticas de investimentos públicos (um exemplo é o Programa de Aceleração do Crescimento - PAC) e sociais que alteraram as características locais. Todavia, a dinâmica foi interrompida por problemas endógenos e exógenos, por falhas e dificuldades de condução (SAWAYA, 2015).

Nessa perspectiva, afirma-se que, no Brasil, existe uma grande quantidade de pessoas que alternam períodos de inserção no mercado de trabalho (quer seja como ocupados - muitas vezes em situações difíceis, do ponto de vista da execução de algum tipo de trabalho, bem como da irregularidade e da instabilidade da remuneração - ou como desempregados) com momentos de inatividade (MATTOS; LIMA, 2015).

Para Vasconcelos e Araújo (2016), a região Nordeste brasileira possui um elevado nível de desigualdade social, apesar de, nos últimos anos, o nível de concentração de renda tenha caído gradativamente. Salienta-se que a queda do grau de concentração da renda está associada às transformações nos rendimentos da renda gerada no emprego.

No Rio Grande do Norte, o cenário é preocupante, pois a unidade federativa tem registrado altos níveis de desocupação nos postos de emprego. Cabe destacar que, em 2016, observava-se o seguinte cenário: os trabalhadores empregados com carteira assinada no Brasil eram 38,2\%; no Nordeste eram 26,3\%; e no Rio Grande do Norte eram apenas 30,8\% (DANTAS; IBGE, 2016).

Nessa perspectiva, o presente artigo objetiva analisar a dinâmica de empregos formais e remunerações no Rio Grande do Norte, no período de 2015-2016. Para uma melhor compreensão do trabalho, este foi estruturado em seções, a saber: introdução na seção 1; revisão teórica na seção 2; metodologia na seção 3; resultados e discussões na seção 4; e, por fim, são realizadas breves considerações finais na seção 5 . 


\section{REVISÃO TEÓRICA}

\section{NOÇÕES SOBRE A CONCEPÇÃO DE EMPREGO}

O termo emprego, da língua inglesa, tem sua origem em 1400 d.C. Até o início do século XVIII, a palavra remetia a alguma tarefa ou determinada empreitada. Sendo assim, não estava ligada a um papel ou uma posição em uma organização. Somente a partir do século XIX, sobreveio o entendimento associado com o trabalho executado nas firmas ou nas burocracias das nações em etapa de industrialização (WOLECK, 2002).

Na América Latina, o debate sobre a abordagem do emprego ganhou impulso e novos rumos a partir dos anos 60, diante de discussões acerca dos efeitos da expansão do capitalismo na periferia do sistema mundial. Naquela ocasião, era atribuído um caráter ruim ao capitalismo implantado no continente latino-americano, pois o crescimento econômico produtivo não correspondia com o aumento necessário de oferta de emprego (AZEVEDO, 1985).

No Brasil, a questão do emprego é uma temática bastante discutida e preocupante dentro da agenda de atividades de curto e médio prazo. Os debates abordam a limitada capacidade do setor formal da economia em absorver o crescimento da mão-de-obra por meio da geração de novos cargos de trabalho e, além disso, a qualidade dos exercícios, que provocam más condições de trabalho (WAJNMAN, 1997).

Emprego pode ser definido como a função e a condição dos indivíduos que exercem algum trabalho, seja de caráter temporário ou permanente, em qualquer tipo de atividade econômica (BRASIL, 2006).

Em sentido amplo, é o uso do fator de produção por uma empresa. Estritamente, é a função, o cargo ou a ocupação remunerada exercida por uma pessoa. A oferta total de empregos que um sistema econômico pode proporcionar depende do que se produz, da tecnologia empregada e da política econômica governamental e empresarial [...] O nível de emprego consiste na relação entre aqueles que podem e desejam trabalhar e os que efetivamente o conseguem, isto é, aqueles que, em tese, são necessários para criar o produto social [...] (SANDRONI, 1999, p. 203).

De acordo com Hackman e Oldham (1976), três fatores são elementares para o emprego ser significativo ao trabalho. São eles: a) A variedade das tarefas; b) Identidade do trabalho; c) Significado do trabalho.

A autonomia gera responsabilidade ao servidor e o feedback contribui na obtenção dos resultados e possíveis ajustes necessários para atingir a meta estimada (HACKMAN; OLDHAM, 1976). Existem cinco regras necessárias de organização do trabalho para compreender as singulares do emprego. São elas: o conjunto de tarefas; a formação da unidade natural de trabalho; o estabelecimento de relações do tipo cliente-fornecedor; o enriquecimento das atividade; e a colocação em prática de instrumentos de feedback acerca do desempenho (MORIN, 2001). 
Nessa perspectiva, Marsden (2004) destaca a relação de emprego como sendo a instituição social e econômica principal nos mercados de trabalho e a base da empresa moderna como organização empregadora. Aqui, é possível perceber como é assegurado os ganhos que derivam da cooperação entre partes auto interessadas, visto que cada uma delas têm conhecimento mais do que a outra sobre elementos importantes de seu trabalho comum, e que a separação entre elas é arriscada.

$\mathrm{Na}$ abordagem de empregos formais, é importante destacar a dinâmica da População Economicamente Ativa (PEA) e a População em Idade Ativa (PIA). A PEA pode ser representada pela seguinte fórmula:

$$
\mathrm{PEA}=\mathrm{PO}+\mathrm{PD}
$$

Em que:

PO representa a população ocupada.

PD representa a população desocupada.

De modo conceitual, a População Economicamente Ativa (PEA) é o grupo de pessoas que se encontram na faixa etária apta ao trabalho. Desse modo, os indivíduos podem estar na categoria de ocupado ou desempregado. Por meio das informações da PEA, é possível alcançar a magnitude da força de trabalho, ou seja, a quantidade populacional que, em determinado período, pressiona o mercado de trabalho (DEDECCA; FERREIRA, 1989).

Já a abordagem da população em idade ativa é dividida em dois grupos: aqueles que não trabalham nem querem exercer a atividade por uma remuneração ou lucro, que formam a população inativa, e aqueles que trabalham por uma remuneração ou lucro ou, não trabalhando, desejam e procuram efetivamente por um trabalho (FERREIRA; LUCIO, 2006).

\section{A REMUNERAÇÃO COMO FATOR MOTIVAÇÃO}

A remuneração, para ser executada, independe de ser um contrato formal, porque se aplica como uma maneira de recompensa por alguma atividade prestada. Logo, a remuneração não se limita ao salário, pois consiste na soma do salário, gratificação, horas extras, prêmios, entre outros possíveis ganhos (FRANCO, 2008).

Nessa perspectiva, é importante estabelecer a distinção entre remuneração e salário. Para Martins (2012), a remuneração é o grupo de prestações recebidas pelo trabalhador por serviços exercidos, podendo ser em dinheiro ou em utilidades provenientes do empregador ou terceiros. Nessa perspectiva, a abordagem da remuneração possui os seguintes elementos: habitualidade; periodicidade; quantificação; essencialidade; e reciprocidade. 
Já o salário ocorre na prestação do serviço que é pago pelo empregador na forma de salário in natura. Pode-se dizer que o salário possui as seguintes características: existência da bilateralidade; caráter alimentar; caráter não-aleatório; proporcionalidade com a natureza da prestação; irredutibilidade e adequação ao custo de vida; e natureza composta (BRASIL, 1943; BRASIL, 1953).

Remunerar estrategicamente significa que as pessoas produzirão mais ao passo que perceberem a possibilidade de ampliarem seus ganhos ao atingirem os objetivos organizacionais (SILVA, 2012). Nessa perspectiva, pode-se dizer que a abordagem da remuneração está vinculada com várias teorias, entre elas, a de equidade e expectativa.

A Teoria da Equidade indica que cenários de justiça ou equidade nas empresas estimulam os trabalhadores, ao contrário de situações de injustiça e assédio moral, que geram insatisfação, mal-estar e ansiedade. Por sua vez, tais sentimentos provocam situações ruins e fazem com que condições de desigualdade possam se estabelecer dentro do ambiente de trabalho. Desse modo, a teoria da equidade evidencia, também, como lidar com esse tipo de circunstância por meio do feedback, salários, benefícios, prazer e status (PAIVA et al., 2009).

Para Bergue (2012), existe uma relação entre a Teoria da Equidade e a remuneração, em que as pessoas observam as remunerações exercidas e os esforços realizados no grupo. Logo, as possíveis comparações são importantes e capazes de interferir no comportamento individual e/ou coletivo. A noção geral de equidade pode ser vista da seguinte forma:

$$
[\mathrm{R} / \mathrm{D}]_{\mathrm{P}}=\left[[\mathrm{R} / \mathrm{D}]_{\mathrm{c}}\right.
$$

Em que:

[R/D] p é a relação entre a remuneração e o desempenho de uma pessoa; e

[R/D] c equivale à relação percebida por colegas ou pelo grupo.

$\mathrm{Se}[\mathrm{R} / \mathrm{D}] \mathrm{p}<[\mathrm{R} / \mathrm{D}] \mathrm{c}$ indica que existe uma remuneração inferior a do colega ou do conjunto de referência e, dessa forma, a situação poderá provocar ausência de motivação do servidor com relação ao trabalho. Por outro lado, quando $[R / D] p=[R / D] c$, a sensação de injustiça poderá existir, ainda que a perca real não alcance o indivíduo, mas, sim, o colega ou grupo de referência (BERGUE, 2012).

A teoria da expectativa aponta que a intensidade do esforço aplicado de uma pessoa está vinculada de forma direta com a expectativa com relação aos possíveis ganhos decorrentes da prática. Essa teoria sugere que uma agradável avaliação de desempenho possibilitará ao servidor recompensas organizacionais (econômicas ou simbólicas) que indicará o alcance de objetivos pessoais (BERGUE, 2012).

No modelo multiplicativo de Victor Vroom são considerados três elementos determinantes. São eles: valência, instrumentalidade e expectância. O primeiro elemento se refere à importância de um fator especifico que é relevante para o individuo de forma singular. A instrumentalidade consiste 
na percepção da relação desempenho - compreensão. Já a expectância se refere à esperança de alcançar as metas estabelecidas (FREIRE; FREITAS, 2007).

\section{METODOLOGIA}

A área de pesquisa se refere ao Estado do Rio Grande do Norte (RN), que é ocupado por 3.168.027 de habitantes, distribuídos em 167 municípios (IBGE, 2016). O Estado do Rio Grande do Norte abrange um território de $52,8 \mathrm{mil} \mathrm{km}^{2}$, o que significa 3,4\% da Região Nordeste, como destaca Bezerra et al. (2015). Ainda segundo o autor, o Estado potiguar é a sexta menor Unidade da Federação em tamanho, ou seja, ocupa apenas $0,6 \%$ da área do país $(8.515,8$ mil km²).

Para a elaboração desse estudo, elegeu-se como base a pesquisa bibliográfica e documental, com a captação e tratamento de dados secundários. Assim, são utilizados os dados do Instituto Brasileiro de Geografia e Estatística (IBGE), que disponibiliza dados estatísticos do Cadastro Central de Empresas (2015). A partir desse levantamento, os dados foram tabulados e analisados na plataforma EXCEL® 2013.

\section{RESULTADOS E DISCUSSÕES}

Nesta seção, serão exibidos os resultados da pesquisa e serão realizadas discussões sobre a temática, aliando dados estatísticos e a abordagem teórica. Nesse sentido, serão observadas informações sobre a quantidade de empregos formais e a remuneração média, por setor da atividade econômica; e o número de empregos formais e remuneração média, classificados por sexo e escolaridade.

Quadro 1 - Número de empregos formais no Rio Grande do Norte, por setor de atividade econômica (2015-2016).

\begin{tabular}{|l|c|c|}
\hline \multicolumn{1}{|c|}{ Setores de Atividades Econômicas } & $\mathbf{2 0 1 5}$ & $\mathbf{2 0 1 6}$ \\
\hline Extrativa mineral & 9.803 & 8.675 \\
\hline Indústria de transformação & 62.794 & 59.104 \\
\hline Serviços industriais de utilidade pública & 6.597 & 6.458 \\
\hline Construção civil & 34.505 & 26.060 \\
\hline Comércio & 119.646 & 114.774 \\
\hline Serviços & 190.737 & 186.003 \\
\hline Administração pública & 168.121 & 167.478 \\
\hline Agropecuária, extr. vegetal, caça e pesca & 16.663 & 17.417 \\
\hline Total & 608.866 & 585.969 \\
\hline
\end{tabular}

Fonte: Adaptado de MTE/CAGED/RAIS, 2016.

De acordo com a quadro 1, o número de empregos formais no RN reduziu boa parte dos setores da atividade econômica. Nessa perspectiva, o segmento da construção civil foi a indústria que mais sentiu os efeitos, dessa forma, havendo uma diminuição de $24,47 \%$, ou 8.445 , nos trabalhadores. 
Nota-se que o cenário de recessão atinge todo o território nacional, conforme afirma a Associação Brasileira da Indústria de Materiais de Construção - ABRAMAT (2017, p. 04) ao afirmar que "a construção, que representa $66,2 \%$ do PIB de toda a cadeia, registrou queda real de $6 \%$. O número de ocupados caiu $2,8 \%$ ".

Considerando que aprimorar a situação ocupacional numa economia gera o aumento do ritmo de crescimento do chamado emprego produtivo, coloca-se como proposta a aplicação de uma política de emprego inserida em proposições de políticas econômicas mais amplas e direcionadas a uma melhor redistribuição de renda e a satisfação das necessidades básicas das pessoas (AZEVEDO, 1981).

Nota-se que as atividades de agropecuária, extração vegetal, caça e pesca aumentaram os números de empregos formais no estado. De modo estatístico, pode-se afirmar que o setor aumentou em 4,52\%, ou seja, 754 novos servidores foram inseridos no mercado de trabalho no estado potiguar.

De acordo com o SEBRAE/RN (2017), no período de 2007-2016, a distribuição dos empregos por atividade econômica foi interferida pela crise, dessa forma, gerando instabilidades. Destaca-se que apenas duas indústrias fogem da premissa. São elas: a indústria médica e a agropecuária.

A distribuição da força de trabalho ocupada em campos econômicos do Rio Grande do Norte, no $1^{\circ}$ trimestre de 2016, tinha o seguinte cenário: o setor primário empregava 7,3\% das pessoas, em atividades da agricultura, pecuária, produção florestal, pesca e aquicultura; o setor secundário computava $25,7 \%$ dos indivíduos ocupados na indústria geral, indústria de transformação e construção civil; o setor terciário reunia $67 \%$ dos trabalhadores na prestação dos seguintes serviços: comércio, reparação de veículos automotores e motocicletas (23,4\%); administração pública, defesa, seguridade social, educação, saúde humana e serviços sociais (20,3\%); informação, comunicação e atividades financeiras, imobiliárias, profissionais e administrativas (8,6\%); alojamento e alimentação (7,3\%); serviços domésticos (6,2\%) e outros serviços (1,2\%) (DANTAS; IBGE, 2016).

Indubitavelmente, a remuneração é um importante elemento que precisa ser analisado. Nesse sentido, a seguir, é possível observar a remuneração média no Rio Grande do Norte, por setor de atividade econômica, no período de 2015-2016.

Quadro 2 - Remuneração média (R\$) no Rio Grande do Norte, por setor de atividade econômica (2015-2016).

\begin{tabular}{|l|c|c|}
\hline \multicolumn{1}{|c|}{ Subsetor de Atividade Econômica } & $\mathbf{2 0 1 5}$ & $\mathbf{2 0 1 6}$ \\
\hline Extrativa mineral & $5.802,33$ & $5.499,60$ \\
\hline Indústria de produtos minerais não metálicos & $1.349,46$ & $1.454,81$ \\
\hline Indústria metalúrgica & $1.568,94$ & $1.525,47$ \\
\hline Indústria mecânica & $2.146,05$ & $2.195,61$ \\
\hline Indústria do material elétrico e de comunicações & $2.497,26$ & $2.790,00$ \\
\hline Indústria do material de transporte & $1.465,97$ & $1.494,05$ \\
\hline Indústria da madeira e do mobiliário & $1.368,81$ & $1.379,05$ \\
\hline Indústria do papel, papelão, editorial e gráfica & $1.401,85$ & $1.354,10$ \\
\hline Ind. da borracha, fumo, couros, peles, similares, ind. Diversas & $1.518,43$ & $1.558,37$ \\
\hline Ind. química de produtos farmacêuticos, veterinários & $3.370,36$ & $2.971,34$ \\
\hline
\end{tabular}




\begin{tabular}{|l|l|l|}
\hline Indústria têxtil do vestuário e artefatos de tecidos & $1.360,22$ & $1.507,69$ \\
\hline Indústria de calçados & $1.115,78$ & $1.118,34$ \\
\hline Indústria de produtos alimentícios, bebidas e álcool etílico & $1.378,47$ & $1.405,36$ \\
\hline Serviços industriais de utilidade pública & $4.022,95$ & $4.201,66$ \\
\hline Construção civil & $1.686,26$ & $1.758,34$ \\
\hline Comércio varejista & $1.292,02$ & $1.327,75$ \\
\hline Comércio atacadista & $1.691,07$ & $1.719,24$ \\
\hline Instituições de crédito, seguros e capitalização & $6.129,55$ & $6.001,16$ \\
\hline Com. e administração de imóveis, valores mobiliários & $1.555,82$ & $1.546,44$ \\
\hline Transportes e comunicações & $2.114,45$ & $2.173,10$ \\
\hline Serv. de alojamento, alimentação, reparação, manutenção & $1.485,69$ & $1.520,57$ \\
\hline Serviços médicos, odontológicos e veterinários & $1.582,20$ & $1.665,64$ \\
\hline Ensino & $4.813,16$ & $4.741,65$ \\
\hline Administração pública direta e autárquica & $3.201,00$ & $3.436,03$ \\
\hline Agricultura, silvicultura, criação de animais & $1.229,91$ & $1.291,14$ \\
\hline Total & $2.305,11$ & $2.388,92$ \\
\hline
\end{tabular}

Fonte: Adaptado de MTE/CAGED/RAIS, 2016.

Considerando a quadro 2, percebe-se que houve alguns setores econômicos que sofreram reduções salariais no período analisado. Nessa perspectiva, menciona-se que as principais indústrias atingidas são: Ind. química de produtos farmacêuticos, veterinários (-11,84\%); Extrativa mineral (-5,22\%); e Ind. do papel, papelão, editorial e gráfica $(-3,41 \%)$.

Por outro lado, nota-se que houve comportamentos crescentes na dimensão da remuneração das seguintes indústrias: material elétrico e de comunicações; têxtil de vestuário e artefatos de tecidos; serviços médicos, odontológicos e veterinários; administração pública direta e autárquica; agricultura, silvicultura, criação de animais. De modo amplo, a remuneração média no RN passou de R \$2.305,11 em 2015 para R 2.388,92 em 2016. A seguir, é exibido o número de empregos formais no Rio Grande do Norte, classificado por sexo e escolaridade.

Quadro 3 - Número de empregos formais no Rio Grande do Norte, por sexo e escolaridade (2015-2016).

\begin{tabular}{|l|c|c|c|c|c|c|}
\hline \multirow{2}{*}{ Escolaridade } & \multicolumn{3}{c|}{$\mathbf{2 0 1 5}$} & \multicolumn{3}{c|}{$\mathbf{2 0 1 6}$} \\
\cline { 2 - 7 } & Masculino & Feminino & Total & Masculino & Feminino & Total \\
\hline Analfabeto & 2.856 & 304 & 3.160 & 2.368 & 284 & 2.652 \\
\hline $5^{\text {a } \text { série incompleta do Ensino Fundamental }}$ & 16.378 & 3.630 & 20.008 & 14.577 & 3.346 & 17.923 \\
\hline $5^{\text {a }}$ série completa do Ensino Fundamental & 11.439 & 3.780 & 15.219 & 10.407 & 3.413 & 13.820 \\
\hline $9^{\text {a } \text { série incompleta do Ensino Fundamental }}$ & 24.205 & 10.298 & 34.503 & 21.780 & 9.137 & 30.917 \\
\hline Ensino Fundamental completo & 31.577 & 13.187 & 44.764 & 27.870 & 11.711 & 39.581 \\
\hline Ensino Médio incompleto & 27.539 & 11.895 & 39.434 & 24.930 & 10.674 & 35.604 \\
\hline Ensino Médio completo & 178.494 & 136.439 & 314.933 & 171.959 & 131.205 & 303.164 \\
\hline Superior incompleto & 7.868 & 9.145 & 17.013 & 8.184 & 9.326 & 17.510 \\
\hline Superior completo & 49.123 & 70.709 & 119.832 & 49.983 & 74.815 & 124.798 \\
\hline Total & 349.479 & 259.387 & 608.866 & 332.058 & 253.911 & 585.969 \\
\hline
\end{tabular}


Considerando os dados de 2015-2016, afirma-se que 51\% dos homens possuem o ensino médio completo; $15 \%$ concluíram o ensino superior; e aproximadamente $0,8 \%$ são analfabetos. Nessa perspectiva, cabe salientar que houve uma redução de analfabetos e pessoas com ensino médio completo. Por sua vez, o número de pessoas que concluíram o ensino superior aumentou. Balassiano, Seabra e Lemos (2005) destacam que a escolaridade é um fator elementar na qualificação dos indivíduos e no aumento de suas remunerações.

Quanto ao sexo feminino, 52\% das mulheres completaram o ensino médio; $28 \%$ detêm ensino superior completo; e $0,11 \%$ são consideradas analfabetas. Similar ao cenário dos homens, nota-se que houve uma redução de pessoas analfabetas, bem como os indivíduos que concluíram o ensino médio. Entretanto, o número de mulheres que concluíram o ensino médio aumentou. Logo, pode-se dizer que as pessoas estão se qualificando cada vez mais e, dessa forma, buscando melhorar a qualidade do serviço prestado.

A qualificação do trabalhador colabora com a empregabilidade do habitante no rigoroso mercado de trabalho, que examina cada vez mais o uso de habilidades técnicas e análise de características comportamentais. Além disso, o investimento das firmas em programas de treinamento interno aos seus servidores pode se tornar uma vantagem competitiva (BORGES, 2016).

De acordo com os dados da Relação Anual de Informações Sociais (RAIS), em 2016, 31\% das pessoas empregadas estavam na faixa etária entre 30 e 39 anos; $22 \%$ possuem entre 40 e 49 anos; $17 \%$ estão na faixa etária entre 50 e 64 anos. Esse resultado indica que as empresas estão optando contratar pessoas mais experientes, pois os cidadãos mais novos não possuem a escolaridade e a qualificação profissional requerida pelas firmas. Nessa perspectiva, a seguir, é exibida, no quadro 4, a remuneração média no Rio Grande do Norte, classificada por sexo e escolaridade.

Quadro 4 - Remuneração média (R\$) no Rio Grande do Norte, por sexo e escolaridade (2015-2016).

\begin{tabular}{|l|c|c|c|c|c|c|}
\hline \multirow{2}{*}{ Escolaridade } & \multicolumn{3}{c|}{$\mathbf{2 0 1 5}$} & \multicolumn{3}{c|}{$\mathbf{2 0 1 6}$} \\
\cline { 2 - 7 } & Masculino & Feminino & Total & Masculino & Feminino & Total \\
\hline Analfabeto & $1.137,33$ & 998,10 & $1.124,08$ & $1.157,13$ & $1.037,14$ & $1.144,54$ \\
\hline $5^{\text {a } \text { série incompleta do Ensino Fundamental }}$ & $1.353,68$ & $1.146,65$ & $1.317,47$ & $1.379,87$ & $1.247,48$ & $1.356,00$ \\
\hline $5^{\text {a }}$ série completa do Ensino Fundamental & $1.532,52$ & $1.207,29$ & $1.453,04$ & $1.638,43$ & $1.312,33$ & $1.559,12$ \\
\hline $9^{\text {a }}$ série incompleta do Ensino Fundamental & $1.764,22$ & $1.388,00$ & $1.651,56$ & $1.824,74$ & $1.419,55$ & $1.704,67$ \\
\hline Ensino Fundamental completo & $1.547,14$ & $1.265,38$ & $1.464,80$ & $1.565,51$ & $1.246,38$ & $1.472,38$ \\
\hline Ensino Médio incompleto & $1.505,95$ & $1.121,30$ & $1.391,07$ & $1.549,81$ & $1.163,09$ & $1.434,94$ \\
\hline Ensino Médio completo & $1.804,74$ & $1.423,90$ & $1.639,88$ & $1.830,54$ & $1.463,50$ & $1.671,91$ \\
\hline Superior incompleto & $2.604,26$ & $1.729,00$ & $2.134,06$ & $2.612,39$ & $1.830,27$ & $2.197,53$ \\
\hline Superior completo & $6.663,27$ & $4.119,13$ & $5.159,68$ & $6.666,63$ & $4.162,80$ & $5.162,13$ \\
\hline Total & $2.424,15$ & $2.144,78$ & $2.305,11$ & $2.499,65$ & $2.243,89$ & $2.388,92$ \\
\hline
\end{tabular}

Fonte: Adaptado de MTE/CAGED/RAIS, 2016.

De modo geral, a remuneração se eleva conforme o aumento da escolaridade dos servidores. Nessa perspectiva, pode-se perceber que, em 2015, as pessoas analfabetas recebiam, em média, 
R\$ 1.124,08, e as os cidadãos com ensino superior completo eram remunerados com R\$ 5.159,68. Logo, percebe-se que, quanto maior a escolaridade e a qualificação profissional do individuo, maior será a remuneração recebida.

Na perspectiva regional, a baixa renda per capita nas regiões Norte e Nordeste está associada com a concentração de pessoas com baixa escolaridade (baixo capital humano) e baixo capital físico, dessa forma, gerando rendas pequenas. Desse modo, faz-se necessária uma política de educação e qualificação profissional e programas de acesso ao crédito (SALVATO; FERREIRA; DUARTE, 2010).

Considerando o período em análise, nota-se que os homens recebem remunerações maiores que as mulheres. De modo numérico, pode-se dizer que a diferença salarial em 2015 foi de R\$279,37; e em 2016, reduziu para $\mathrm{R} \$ 255,76$. O resultado aponta para a diferença salarial entre os gêneros que, por sua vez, pode prejudicar o desenvolvimento socioeconômico local.

No decorrer dos últimos anos, com o aumento da taxa de atividade feminina, o perfil da mulher no mercado de trabalho mudou. Dessa forma, a maior introdução e valorização da mão de obra feminina no mercado de trabalho gera menores diferenças salariais entre os gêneros. Todavia, ainda há um logo percurso a ser percorrido para alcançar a igualdade (CASTRO; STAMM, 2016).

\section{CONSIDERAÇÕES FINAIS}

Por meio de informações obtidas através de fontes oficiais, buscou-se responder a problemática inicial, que se concentrava em analisar a dinâmica de empregos formais e remunerações no Rio Grande do Norte no período de 2015-2016. Nessa perspectiva, foram buscados dados que retratam o comportamento das variáveis emprego e remuneração no RN.

Diante da classificação por setor de atividade econômica, notou-se que o número de empregos no Rio Grande do Norte diminuiu de modo significativo. A indústria da construção civil apresentou a maior queda no período estimado. Por outro lado, a agropecuária, extração vegetal, a caça e a pesca são consideradas como exceções, pois foram os únicos segmentos que tiveram crescimento produtivo.

$\mathrm{Na}$ abordagem das remunerações, a indústria química de produtos farmacêuticos e veterinários teve a maior queda, na medida em que a indústria do material elétrico e de comunicações obteve o maior crescimento entre os setores analisados. Nessa perspectiva, afirma-se que a média da remuneração aumentou em boa parte dos setores econômicos no Estado do Rio Grande do Norte.

Percebe-se que o número de pessoas com a escolaridade baixa diminuiu e, dessa forma, reduziu-se a quantidade de indivíduos analfabetos. Seguindo essa linha de raciocínio, notou-se que o número de pessoas que concluíram o ensino superior aumentou de maneira significativa. Nessa perspectiva, o aumento da escolaridade aponta para o incremento salarial.

Acredita-se que o Estado do Rio Grande do Norte obteve conquistas ímpares no decorrer dos anos, assim, capacitando os cidadãos, melhorando as remunerações e aumentando a qualidade de 
vida dos habitantes locais. Entretanto, ainda há um longo caminho a ser percorrido a fim de reduzir/ excluir as disparidades sociais, econômicas e políticas.

Em pesquisas futuras, sugere-se o aprofundamento na modelagem das variáveis de estudo com uso de alguma ferramenta estatística aplicada ao modelo econométrico escolhido. Desse modo, será possível aprimorar os resultados da análise e melhorar a compreensão da situação do estado potiguar brasileiro.

\section{REFERÊNCIAS}

ABRAMAT - Associação Brasileira da Indústria de Materiais de Construção. Perfil da Industria de Materiais de Construção - 2017. Disponível em: http://www.abramat.org.br. Acesso em: 16 mai. 2018.

AZEVEDO, B. R. Z de. Emprego, desemprego e subemprego: uma revisão literária crítica. Ensaios FEE. Porto Alegre, v. 6, nº 1, p. 155-168, 1985.

. Emprego, salário e pobreza. Ensaios FEE. Porto Alegre, v. 2, nº 2, p. 135-141, 1981.

BALASSIANO, M.; SEABRA, A. A de.; LEMOS, A. H. Escolaridade, Salários e Empregabilidade: Tem Razão a Teoria do Capital Humano? Revista de Administração Contemporânea, v. 9, n. 4, p. 31-52. 2005.

BERGUE, S. T. Comportamento organizacional. 2. ed. reimp. - Florianópolis. 2012.

BEZERRA, F. J. A. Perfil socioeconômico do Rio Grande do Norte. Fortaleza: Banco do Nordeste do Brasil, 2015.

BORGES, J. C. A qualificação profissional do trabalhador para o mercado de trabalho e ambiente organizacional. In: Seminário Nacional de Desenvolvimento Regional. Taquara - RS, 2016.

BRASIL. Decreto-lei n. ${ }^{\circ}$ 5.452, de $1^{\circ}$ de maio de 1943. Aprova a Consolidação das Leis do Trabalho. Disponível em: http://www.planalto.gov.br. Acesso em: 24 mai. 2018.

Lei $\mathbf{n}^{0} \mathbf{1 . 9 9 9}$, de $1^{\circ}$ de outubro de 1953. Modifica o art. 457 e seus parágrafos do Decreto-lei $\mathrm{n}^{\mathrm{o}}$ 5.452, de $1^{\text {o }}$ de maio de 1943 (Consolidação das Leis do Trabalho). Disponível em: http://www. planalto.gov.br. Acesso em: 24 mai. 2018. 
. Ministério de Educação. Secretaria de Educação Continuada, Alfabetização e Diversidade.

Emprego e Trabalho. Coleção Cadernos de EJA. 2006.

. Ministério do Trabalho - MTE. Cadastro Geral de Empregados e Desempregados CAGED. Relação Anual das Informações Sociais - RAIS. Dados Estatuais 2016. Disponível em: www.mte.gov.br. Acesso em: 09 mai. 2018.

CASTRO, B. N.; STAMM, C. Diferenças salariais de gênero e raça no mercado de trabalho brasileiro: uma analise estatística e econométrica. In: XX Encontro Nacional de Estudo de População. Foz do Iguaçu-PR. 2016.

DANTAS, A. A. O desemprego no Brasil e no Rio Grande do Norte. 2016. Disponível em: www. corecon-rn.org.br. Acesso em: 19 mai. 2018.

DEDECCA, C. S.; FERREIRA, S. P. Transição demográfica e crescimento da população economicamente ativa. São Paulo em Perspectiva. v.3 n.3, p. 79-83. 1989.

FERREIRA, S. P.; LUCIO, C. G. Pesquisa de emprego e desemprego: inovações conceituais e institucionais. São Paulo em Perspectiva, v. 20, n. 4, p. 5-17. 2006.

FRANCO, J de. O. Cargos, salários e remunerações. Curitiba: IESDE Brasil S.A, 2008.

FREIRE, A. C.; FREITAS, L. S. Aplicação da Teoria da Expectância de Vroom na perspectiva de jovens em seus primeiros empregos. In: Jornadas Espanholas. Univeridad de La Rioja. La Rioja (Espanha), 2007.

HACKMAN, J. R., OLDHAM, G. R. Motivation through the design of work: test of a theory. Organizational Behavior and Human Performance, v. 16, p. 250-279, 1976.

IBGE. Instituto Brasileiro de Geografia e Estatística. Pesquisa Nacional por Amostra de Domicílios Contínua - PNAD Contínua. 2016. Disponível em: ww2.ibge.gov.br. Acesso em: 19 mai. 2018.

MARSDEN, D. Sistemas de emprego, estratégias de gestão e instituições do trabalho. Revista de sociologia da USP, v. 16, n. 2, p. 225-255, 2004. 
MARTINS, S. P. Direito do Trabalho. Ed. 28. São Paulo: Atlas, 2012.

MATTOS, F. A. M de; LIMA, S da. S. Apontamentos para o debate sobre o pleno emprego no Brasil. Revista Economia e Sociedade. v. 24, n. 2 v.54, p. 293-328. Campinas-SP, 2015.

PAIVA, C. P; ADAS, L. D dos. S; VENDRAME, F. C; SARRACENI, J. M; VENRAME, M de. C. R. Uma abordagem às teorias motivacionais. In: II Encontro Científico II Simpósio de Educação Unisalesiano. Lins - SP, 2009.

SALVATO, M. A.; FERREIRA, P. C. G.; DUARTE, A. J. M. O Impacto da Escolaridade Sobre a Distribuição de Renda. Revista Estudos Econômicos. v. 40, n. 4, p. 753-791. São Paulo, 2010.

SANDRONI, P. Novíssimo dicionário de economia. Ed. Best Seller, 1999.

SEBRAE. Serviço de Apoio às micro e pequenas empresas do Rio Grande do Norte. Análise da Evolução do Mercado de Trabalho Formal. 2017. Disponível em: m.sebrae.com.br. Acesso em: 19 mai. 2018.

SILVA, J. A. G da. Remuneração como fator motivacional: tem razão a teoria da expectância? FOCO: Revista de Administração da Faculdade Novo Milênio. v. 6, n. 1, 2013.

VASCONCELOS, J. C.; ARAUJO, J. A. Efeitos distributivos do salário mínimo no mercado de trabalho da Região Nordeste. Revista de Economia Contemporânea. Rio de Janeiro, v. 20, n. 2 , p. 359-385, 2016.

WAJNMAN, S. Tendências prospectivas de crescimento da população economicamente ativa no Brasil - Belo Horizonte: CEDEPLARI UFMG, 1997.

WOLECK, A. O. Trabalho, a ocupação e o emprego. Uma perspectiva Histórica. Revista de Divulgação Técnico-científica do Instituto Catarinense de Pós-Graduação, p. 33-39, 01 jan. 2002. 
